\title{
Pre-endoscopic erythromycin administration in upper gastrointestinal bleeding: an updated meta-analysis and systematic review
}

\author{
Rubayat Rahmana, Douglas L. Nguyen ${ }^{b}$, Umair Sohaila , Ashraf A. Almashhrawia, Imran Ashrafa, \\ Srinivas R. Pulic, Matthew L. Bechtold ${ }^{a}$
}

University of Missouri Health Sciences Center; University of California-Irvine; University of Illionois-Peoria, USA

\begin{abstract}
Background In patients suffering from upper gastrointestinal bleeding (UGIB), adequate visualization is essential during endoscopy. Prior to endoscopy, erythromycin administration has been shown to enhance visualization in these patients; however, guidelines have not fully adopted this practice. Thus, we performed a comprehensive, up-to-date meta-analysis on the issue of erythromycin administration in this patient population.

Methods After searching multiple databases (November 2015), randomized controlled trials on adult subjects comparing administration of erythromycin before endoscopy in UGIB patients to no erythromycin or placebo were included. Pooled estimates of adequacy of gastric mucosa visualized, need for second endoscopy, duration of procedure, length of hospital stay, units of blood transfused, and need for emergent surgery using odds ratio (OR) or mean difference (MD) were calculated. Heterogeneity and publication bias were assessed.

Results Eight studies $(n=598)$ were found to meet the inclusion criteria. Erythromycin administration showed statistically significant improvement in adequate gastric mucosa visualization (OR 4.14; 95\% CI: 2.01-8.53, $\mathrm{P}<0.01$ ) while reduced the need for a second-look endoscopy (OR 0.51; 95\% CI: 0.34-0.77, $\mathrm{P}<0.01$ ) and length of hospital stay (MD -1.75; 95\% CI: -2.43 to $-1.06, \mathrm{P}<0.01)$. Duration of procedure $(\mathrm{P}=0.2)$, units of blood transfused $(\mathrm{P}=0.08)$, and need for emergent surgery $(\mathrm{P}=0.88)$ showed no significant differences.
\end{abstract}

Conclusion Pre-endoscopic erythromycin administration in UGIB patients significantly improves gastric mucosa visualization while reducing length of hospital stay and the need for second-look endoscopy.

Keywords Erythromycin, bleeding, endoscopy

Ann Gastroenterol 2016; 29 (3):1-6

Division of ${ }^{\mathrm{a}}$ Gastroenterology and Hepatology, University of Missouri Health Sciences Center (Rubayat Rahman, Umair Sohail, Ashraf A. Almashhrawi, Imran Ashraf, Matthew L. Bechtold); ${ }^{\mathrm{b}}$ Gastroenterology and Hepatology, University of California-Irvine (Douglas L. Nguyen); ' Gastroenterology and Hepatology, University of Illinois-Peoria (Srinivas R. Puli), USA

\section{Conflict of Interest: None}

Correspondence to: Matthew L. Bechtold, MD, FACP, FASGE, FACG, AGAF, Ass. Professor of Clinical Medicine, Division of Gastroenterology and Hepatology, CE405, DC 043.00, University of Missouri Health Sciences Center, Five Hospital Drive, Columbia, MO 65212, USA, Tel.: +1 573882 1013, Fax: +1 573 8844595,

e-mail: bechtoldm@health.missouri.edu

Received 19 February 2015; accepted 09 April 2016;

Published online 20 May 2016

DOI: http://dx.doi.org/10.20524/aog.2016.0045

\section{Introduction}

Upper gastrointestinal bleeding (UGIB) is a medical condition that is associated with significant morbidity and healthcare cost burden. The incidence and mortality of UGIB may range from 48-160 adult cases per 100,000 per year and $10-14 \%$, respectively [1]. The estimated direct costs for management of UGIB in the USA are over 1 billion dollars (US) annually [2]. Endoscopic treatment may improve immediate and delayed clinical outcomes. But there is one global challenge of urgent esophagogastroduodenoscopy (EGD) and that is the presence of retained blood or other residual material in the stomach, which may interfere not only with endoscopic evaluation but also with both immediate and delayed outcome of UGIB management [3]. Various methods including gastric lavage may affect and reduce the interference of retained blood 
clot or other residual materials in emergent EGD but due to its own morbidity and time consumption, the outcomes were not satisfactory [4].

On the other hand, erythromycin is a cost-effective, macrolide antibiotic which is a motilin receptor agonist [5]. It is also known to induce gastric motility that can translate into effective gastric emptying before emergent endoscopy. In multiple studies, it was shown that early administration of erythromycin before endoscopy in acute UGIB can have positive outcomes in the need for second-look endoscopy, endoscopic visualization, blood transfusions, hospital stay, procedure duration, and mortality [6-9]. But the individual randomized trials did not have large number of subjects and there has been no recent meta-analysis that included all the trials examining both the clinical and economic outcomes of erythromycin administration before endoscopy for acute UGIB.

The aim of our study was to perform an up-to-date metaanalysis with all the available randomized clinical trials and evaluate the use of erythromycin administration prior to endoscopy for acute UGIB patients in regard to adequate visualization, need for second endoscopy, hospital length of stay, and need for blood transfusion.

\section{Materials and methods}

\section{Literature search}

A literature search was performed in November 2015 consisting of three well-known search strategies. First, a search of popular databases, including Medline/PubMed, Scopus, CINAHL, and the Cochrane databases, was performed using erythromycin, endoscopy, and bleeding ("erythromycin"[MeSH Terms] OR “erythromycin”[All Fields]) AND ("endoscopy"[MeSH Terms] OR "endoscopy" [All Fields]) AND ("hemorrhage" [MeSH Terms] OR "hemorrhage"[All Fields] OR "bleeding" [All Fields]). Second, a search of abstracts from major meetings in gastroenterology, including those from Digestive Disease Week and the American College of Gastroenterology national meeting, was conducted over the last decade. Lastly, all references were searched in each article identified in an effort to reduce exclusion of potential articles. If any data was missing or questionable, authors were contacted for clarification. All articles in English and Polish were included.

\section{Data extraction}

Data extraction was conducted by two independent reviewers (RR, MLB) from all included studies using a standardized data extraction sheet. Any disagreement among those two reviewers was settled by mutual agreement or involvement of a third party reviewer (DN).

\section{Statistical analysis}

Studies on adult patients with UGIB that compared erythromycin administration before endoscopy to no erythromycin or placebo were identified and used in this metaanalysis. Data was collected for the following outcomes: gastric visualization, need for second-look endoscopy, units of blood transfused, length of endoscopy, length of hospital stay, and need for emergent surgery. The data was pooled, analyzed, and reported as odds ratio (OR), for dichotomous data, and mean difference (MD), for continuous data, using the Mantel-Haenszel (fixed effect) model in outcomes with no heterogeneity and the DerSimonian and Laird (random effects) model in outcomes with significant heterogeneity. Heterogeneity among pooled studies was calculated using the $\mathrm{I}^{2}$ measure of inconsistency (significant if $\mathrm{P}<0.10$ or $\mathrm{I}^{2}>50 \%$ ). If heterogeneity was discovered, the random effects model was utilized as well as a sensitivity analysis performed by removing the least amount of studies necessary to reach non-significant heterogeneity and comparing results to the original pooled data. Data was analyzed by using RevMan 5.3 (Review Manager, Version 5.3, Copenhagen: The Nordic Cochrane Centre, The Cochrane Collaboration, 2012). Publication bias was assessed using funnel plots.

\section{Quality assessment of studies}

The Cochrane's Collaboration Risk of Bias Tool was used to assess the quality of included studies [10]. In this tool, each outcome was given a GRADE (very low, low, moderate, or high) based on the quality of evidence. The parameters evaluated in each study were as follows: precision, consistency of results, effect magnitude, and potential bias (publication and other forms) [10].

\section{Results}

\section{Selection of studies}

After a comprehensive search, 229 potential articles were identified (Fig. 1). Of these articles, based upon title and abstract, 20 studies were examined more closely. After full text examination, eight studies met the inclusion criteria. Details of the included studies are found in Table 1.

\section{Quality assessment of studies}

The quality of the studies included in this meta-analysis was extensively evaluated using Cochrane's Collaboration Risk of Bias Tool [10]. Details of quality assessment described in Table 2.

\section{Visualization of the gastric mucosa}

Gastric visualization was evaluated in all eight included studies $(n=598)$ [11-18]. Adequate gastric visualization was 


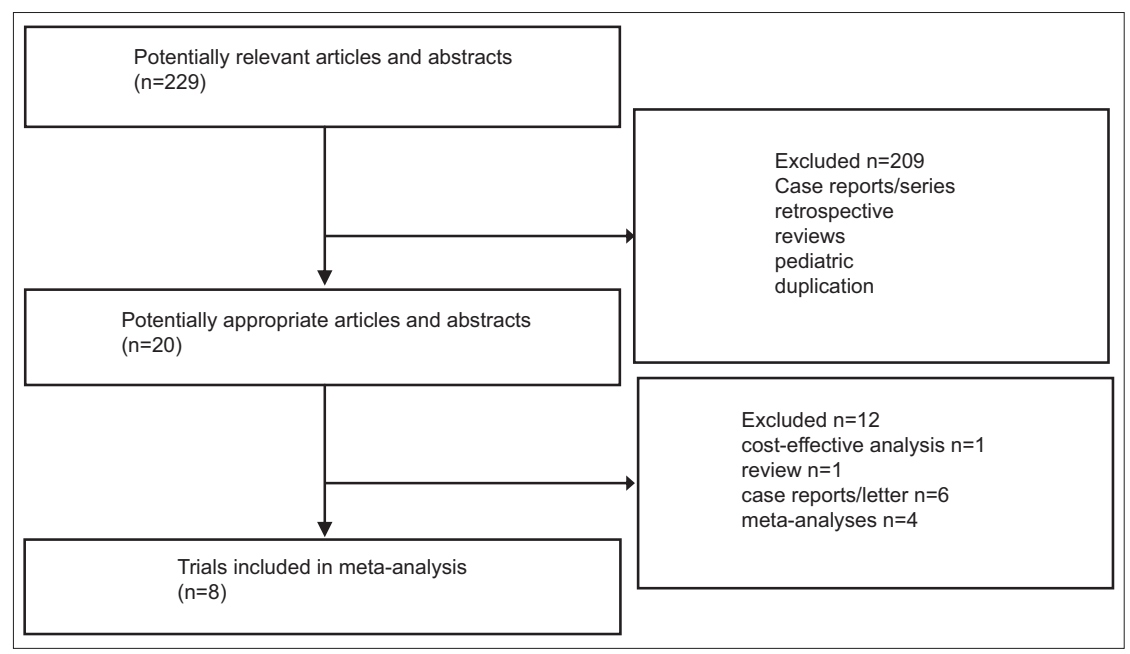

Figure 1 Article search details in November 2015

Table 1 Details of the included studies

\begin{tabular}{|c|c|c|c|c|c|c|c|}
\hline Author & $\begin{array}{l}\text { Study } \\
\text { type }\end{array}$ & Blinded & Location & $\begin{array}{l}\text { Number } \\
\text { of patients }\end{array}$ & $\begin{array}{l}\text { Erythromycin } \\
\text { dose }\end{array}$ & $\begin{array}{l}\text { Erythromycin } \\
\text { infusion time } \\
\quad(\min )\end{array}$ & $\begin{array}{c}\text { Post-infusion } \\
\text { EGD start } \\
\text { time (min) }\end{array}$ \\
\hline Carbonell et al 2004 [11] & RCT & Yes & France & 99 & $250 \mathrm{mg}$ & 30 & 30 \\
\hline Frossard et al 2002 [13] & RCT & Yes & Switzerland & 105 & $250 \mathrm{mg}$ & 5 & 20 \\
\hline Coffin et al 2002 [12] & RCT & Yes & France & 41 & $3 \mathrm{mg} / \mathrm{kg}$ & 30 & $30-90$ \\
\hline Rudzki et al 2006 [16] & RCT & No & Poland & 24 & $4 \mathrm{mg} / \mathrm{kg}$ & 9 & $30-90$ \\
\hline Altraif et al 2011 [14] & RCT & Yes & Saudi Arabia & 90 & $125 \mathrm{mg}$ & 10 & 30 \\
\hline Pateron et al 2011 [15] & RCT & No & France & 169 & $250 \mathrm{mg}$ & 20 & 30 \\
\hline Ardakani et al 2013 [18] & RCT & Yes & Iran & 40 & $3 \mathrm{mg} / \mathrm{kg}$ & 5 & $30-60$ \\
\hline Habashi et al 2007 - abstract [17] & RCT & Yes & United States & 30 & NA & NA & NA \\
\hline
\end{tabular}

$R C T$, randomized controlled trial; $N A$, not available

Table 2 Quality assessment summary of all included studies

\begin{tabular}{|c|c|c|c|c|c|c|c|c|c|}
\hline Study & $\begin{array}{l}\text { Study } \\
\text { design }\end{array}$ & $\begin{array}{l}\text { Random } \\
\text { sequence } \\
\text { generation }\end{array}$ & $\begin{array}{l}\text { Allocation } \\
\text { concealment }\end{array}$ & Blinding & $\begin{array}{l}\text { Blinding } \\
\text { outcome } \\
\text { assessment }\end{array}$ & $\begin{array}{l}\text { Incomplete } \\
\text { outcome } \\
\text { data }\end{array}$ & $\begin{array}{l}\text { Selective } \\
\text { reporting }\end{array}$ & $\begin{array}{l}\text { Other } \\
\text { bias }\end{array}$ & $\begin{array}{l}\text { Quality } \\
\text { assessment }\end{array}$ \\
\hline Carbonell et al 2004 [11] & RCT & Adequate & Adequate & Double-blinded & Adequate & None & None & None & High \\
\hline Frossard et al 2002 [13] & RCT & Adequate & Adequate & Double-blinded & Adequate & None & None & None & High \\
\hline Coffin et al 2002 [12] & RCT & Adequate & Inadequate & Single-blinded & Adequate & None & None & None & Moderate \\
\hline Rudzki et al 2006 [16] & RCT & Adequate & Not described & None & Inadequate & None & None & None & Low \\
\hline Altraif et al 2011 [14] & RCT & Adequate & Adequate & Double-blinded & Adequate & None & None & None & High \\
\hline Pateron et al 2011 [15] & RCT & Adequate & Adequate & Single-blinded & Adequate & None & None & None & Moderate \\
\hline Ardakani et al 2013 [18] & RCT & Not described & Not described & Double-blinded & Adequate & None & None & None & Low \\
\hline $\begin{array}{l}\text { Habashi et al } 2007 \text { - } \\
\text { abstract [17] }\end{array}$ & RCT & Not described & Adequate & Double-blinded & Adequate & None & None & None & Moderate \\
\hline
\end{tabular}

$R C T$, randomized controlled trial

assessed in each study by a dichotomous method and divided as adequate or inadequate visualization of gastric mucosa. Adequate gastric visualization was observed in 229/298 (76.8\%) patients who received erythromycin before endoscopy and $152 / 300(50.7 \%)$ who received no erythromycin or placebo. Upon pooling of data, erythromycin given before endoscopy in UGIB patients resulted in a statistically significant higher odds of adequate gastric visualization compared to no erythromycin or placebo (OR 4.14; 95\% CI: 2.01-8.53; $\mathrm{P}<0.01$ ) (Fig. 2). Heterogeneity was found at a significant level $\left(\mathrm{I}^{2}=64 \%\right.$, $\mathrm{P}<0.01)$. Sensitivity analysis was performed and after removing one study [15] and revealed similar results (OR 5.13; 95\% CI: 
2.66-9.87; $\mathrm{P}<0.01)$ with no significant heterogeneity $\left(\mathrm{I}^{2}=42 \%\right.$, $\mathrm{P}=0.11$ ). The number needed to treat with erythromycin to optimize gastric visualization was four patients. Publication bias was non-significant.

\section{Need for second-look endoscopy}

If adequate visualization of the mucosa is not apparent, a second-look endoscopy may be required. All eight studies evaluated the need a second endoscopy $(n=598)$ [11-18]. Second-look endoscopy was necessary in $45 / 298$ (15.1\%) in the erythromycin group and 77/300 (25.7\%) in the no erythromycin group. Upon pooling of the data, the odds of needing a secondlook endoscopy was statistically reduced in the erythromycin group compared to no erythromycin group (OR 0.51; 95\% CI: 0.34-0.77; $\mathrm{P}<0.01$ ) (Fig. 3). Heterogeneity $\left(\mathrm{I}^{2}=24 \%, \mathrm{P}=0.24\right)$ and publication bias were found to be non-significant. Overall, the number of patients needed to treat with erythromycin to prevent a need for second-look endoscopy was nine patients.

\section{Blood transfusion}

Blood transfusion was reported in six of the studies $(n=544)$ [11-15,18]. This outcome was reported as mean number of packed red blood cells required for each patient with UGIB. Unlike meta-analyses in the past, the administration of erythromycin showed no statistically significant difference to no erythromycin for amount of blood transfusions required
(MD -1.06; 95\% CI: -2.24-0.13; $\mathrm{P}=0.08$ ); Table 3. This result may be due to significant heterogeneity $\left(\mathrm{I}^{2}=89 \%, \mathrm{P}<0.01\right)$. Upon sensitivity analysis of one study's removal [18], no heterogeneity was identified $\left(\mathrm{I}^{2}=0 \%, \mathrm{P}=0.85\right)$ and the results demonstrated that erythromycin administration decreased the amount of blood transfusions compared to no erythromycin (MD -0.41; 95\% CI: -0.82 to $-0.01 ; \mathrm{P}=0.04$ ). Publication bias was not apparent.

\section{Length of hospital stay}

Hospital stay was evaluated in five studies $(n=375)$ by mean number of days spent in the hospital [11-14,18]. The use of preprocedure erythromycin showed a statistically significant odds of fewer days in the hospital stay (MD $-1.75 ; 95 \%$ CI: -2.43 to $-1.06, \mathrm{P}<0.01$ ) compared to the no erythromycin (Table 3 ). The heterogeneity was found to be insignificant $\left(\mathrm{I}^{2}=0 \%\right.$, $\mathrm{P}=0.55$ ) and no publication bias observed.

\section{Duration of procedure}

Endoscopy duration, measured by mean minutes of the procedure, was assessed in five studies $(n=503)[11,13-15,18]$. Endoscopy duration was not statistically significant (MD -4.94; 95\% CI: -12.42-2.54; $\mathrm{P}=0.20$ ) with no publication bias found (Table 3). However, statistically significant heterogeneity was observed $\left(\mathrm{I}^{2}=96 \%, \mathrm{P}<0.01\right)$ and a sensitivity analysis

\begin{tabular}{|c|c|c|c|c|c|c|c|c|c|}
\hline \multirow[b]{2}{*}{ Study or Subgroup } & \multicolumn{2}{|c|}{ Erythromycin } & \multicolumn{2}{|c|}{ No Erythrormycin } & \multirow[b]{2}{*}{ Weight } & \multirow{2}{*}{$\begin{array}{c}\text { Odds Ratio } \\
\text { M.H, Random, } 95 \% \mathrm{Cl}\end{array}$} & \multirow{2}{*}{\multicolumn{3}{|c|}{$\begin{array}{c}\text { Odds Ratio } \\
\text { M.H, Random, } 95 \% \mathrm{Cl}\end{array}$}} \\
\hline & Events & Total & Events & Total & & & & & \\
\hline Altraif et al 2011 [14] & 23 & 47 & 10 & 43 & $16.4 \%$ & $3.16[1.27,7.85]$ & & & \\
\hline Ardakani et al 2013 [18] & 20 & 20 & 5 & 20 & $4.7 \%$ & $115.55[5.93,2250.57]$ & & & \\
\hline Carbonell et al 2006 [11] & 34 & 49 & 24 & 50 & $17.2 \%$ & $2.46[1.08,5.59]$ & & & \\
\hline Coffin et al 2002 [12] & 17 & 19 & 12 & 22 & $10.0 \%$ & $7.08[1.31,38.33]$ & & & \\
\hline Frossard et al 2002 [13] & 42 & 51 & 18 & 54 & $16.3 \%$ & $9.33[3.74,23.32]$ & & & $\longrightarrow$ \\
\hline Habashi et al 2007 [17] & 13 & 15 & 10 & 15 & $9.1 \%$ & $3.25[0.52,20.37]$ & & - & \\
\hline Pateron et al 2011 [15] & 69 & 84 & 68 & 85 & $17.7 \%$ & $1.15[0.53,2.49]$ & & & 5 \\
\hline Rudzki et al 2006 [16] & 11 & 13 & 5 & 11 & $8.6 \%$ & $6.60[0.97,44.93]$ & & & \\
\hline Total $(95 \% \mathrm{Cl})$ & & 298 & & 300 & $100.0 \%$ & $4.14[2.01,8.53]$ & & & \\
\hline Total events & 229 & & 152 & & & & & & \\
\hline $\begin{array}{l}\text { Heterogeneity. } \text { Tau }^{2}=0.62 \\
\text { Test for overall effect } Z=\end{array}$ & $\begin{array}{l}\mathrm{Chi}^{2}=19 \\
85(\mathrm{P}=0\end{array}$ & $\begin{array}{l}66, d f= \\
001)\end{array}$ & $7(P=0.00$ & $1^{2}=64$ & & & $\begin{array}{ll}0.01 & 0.1 \\
\text { Favors No Eryt }\end{array}$ & thromycin & $\begin{array}{cc}10 & 100 \\
\text { Favors Enythromycin }\end{array}$ \\
\hline
\end{tabular}

Figure 2 Forest plot comparing erythromycin to no erythromycin for adequacy of gastric visualization

\begin{tabular}{|c|c|c|c|c|c|c|c|c|}
\hline \multirow[b]{2}{*}{ Study or Subgroup } & \multicolumn{2}{|c|}{ Erythromycin } & \multicolumn{2}{|c|}{ No Erythromycin } & \multirow[b]{2}{*}{ Weight } & \multirow{2}{*}{$\begin{array}{c}\text { Odds Ratio } \\
\text { M-H, Fixed, } 95 \% \mathrm{Cl}\end{array}$} & \multirow{2}{*}{\multicolumn{2}{|c|}{$\begin{array}{c}\text { Odds Ratio } \\
\text { M-H, Fixed, } 95 \% \mathrm{Cl}\end{array}$}} \\
\hline & Events & Total & Events & Total & & & & \\
\hline Altraif et al 2011 [14] & 2 & 47 & 4 & 43 & $6.3 \%$ & $0.43[0.08,2.50]$ & & \\
\hline Ardakani et al 2013 [18] & 1 & 20 & 3 & 20 & $4.5 \%$ & $0.30[0.03,3.15]$ & & \\
\hline Carbonell et al 2006 [11] & 12 & 49 & 12 & 50 & $14.1 \%$ & $1.03[0.41,2.58]$ & & \\
\hline Coffin et al 2002 [12] & 3 & 19 & 10 & 22 & $12.3 \%$ & $0.23[0.05,1.00]$ & & \\
\hline Frossard et al 2002 [13] & 6 & 51 & 17 & 54 & $22.9 \%$ & $0.29[0.10,0.81]$ & $\longrightarrow-$ & \\
\hline Habashi et al 2007 [17] & 1 & 15 & 3 & 15 & $4.4 \%$ & $0.29[0.03,3.12]$ & & \\
\hline Pateron et al 2011 [15] & 17 & 84 & 20 & 85 & $25.0 \%$ & $0.82[0.40,1.71]$ & $\rightarrow$ & - \\
\hline Rudzki et al 2006 [16] & 3 & 13 & 8 & 11 & $10.5 \%$ & $0.11[0.02,0.72]$ & & \\
\hline Total $(95 \% \mathrm{Cl})$ & & 298 & & 300 & $100.0 \%$ & $0.51[0.34,0.77]$ & & \\
\hline Total events & 45 & & 77 & & & & & \\
\hline $\begin{array}{l}\text { Heterogeneity. } \mathrm{Chi}^{2}=9.22 \\
\text { Test for overall effect: } \mathrm{Z}=\end{array}$ & $\begin{array}{l}d f=7(P= \\
17(P=0 .\end{array}$ & $\begin{array}{l}0.24) ; 1^{2} \\
02)\end{array}$ & $=24 \%$ & & & & $\begin{array}{ll}0.01 & 0.1 \\
\text { Favors Erythromycin }\end{array}$ & \begin{tabular}{|cc}
10 & 100 \\
Favors No Enythromycin
\end{tabular} \\
\hline
\end{tabular}

Figure 3 Forest plot comparing erythromycin to no erythromycin for second-look endoscopy 
Table 3 Outcomes of comparisons of erythromycin to no erythromycin for units of blood transfused, length of hospital stay, duration of procedure, and need for emergent surgery

\begin{tabular}{|c|c|c|c|c|}
\hline Outcome & $\begin{array}{l}\text { Analysis } \\
\text { outcome }\end{array}$ & $\begin{array}{l}95 \% \text { confidence } \\
\text { interval }\end{array}$ & P-value & $\begin{array}{l}\mathrm{I}^{2} \\
(\%)\end{array}$ \\
\hline Units of blood transfused & $-1.06^{*}$ & -2.24 to 0.13 & 0.08 & 89 \\
\hline Length of hospital stay & $-1.75^{*}$ & -2.43 to -1.06 & $<0.01$ & 0 \\
\hline Duration of procedure & $-4.94^{*}$ & -12.42 to 2.54 & 0.20 & 96 \\
\hline Need for emergent surgery & $1.11^{* *}$ & $0.27-4.67$ & 0.88 & 44 \\
\hline
\end{tabular}

was conducted showing no significant change in the results (MD 1.46; 95\% CI: $-0.76-3.68, \mathrm{P}=0.20$ ) with no heterogeneity $\left(\mathrm{I}^{2}=0 \%, \mathrm{P}=0.67\right)$ when three studies were removed $[13,14,18]$.

\section{Need for emergent surgery}

The need for emergent surgery was analyzed by two studies $(n=146)[12,13]$. No difference was observed for the need for emergent surgery between those patients receiving preendoscopic erythromycin $(4 / 70,1.4 \%)$ compared to those not receiving erythromycin $(4 / 76,5.3 \%$ ) (OR 1.11 ; 95\% CI: $0.27-4.67 ; \mathrm{P}=0.88)$ with no publication bias or significant heterogeneity (Table 3 ).

\section{Discussion}

UGIB is a life-threatening condition that requires prompt recognition and management. Erythromycin administration before endoscopy in patients with UGIB has been shown useful in many randomized controlled trials (RCTs) to help with visualization of gastric mucosa. However, guidelines have been slow to evolve.

In 2010, the international consensus recommendations by Barkun et al [1] were published and despite the five published RCTs $[11-13,16,17]$ and one meta-analysis [6] on the subject of erythromycin at time, the group recommended that promotility agents should not be routinely used prior to endoscopy in UGIB patients [1]. However, this recommendation included trials using erythromycin and metoclopramide which likely influenced the outcome consensus as metoclopramide seems to be less effective [19]. In 2011, two meta-analyses [7,8] were published including only studies using erythromycin and discovered that the use of erythromycin prior to endoscopy increased the odds of adequate gastric visualization while decreasing the odds of a second-look endoscopy. Subsequently in 2011, two additional RCTs on the subject were published $[14,15]$. Based on these new studies and metaanalyses, in 2012, the American Society for Gastrointestinal Endoscopy recommended the possibility of using a prokinetic agent prior to endoscopy in patients with high probability of fresh blood or clots in stomach but not for routine use [20]. Also, in 2012, the American College of Gastroenterology recommended pre-procedure erythromycin in UGIB patients should be considered for increasing diagnostic yield and decreasing need for second-look endoscopy [3]. However, this guideline stated that erythromycin did not consistently improve clinical outcomes [3]. In 2013, a meta-analysis of six studies $(n=558)$ was repeated showing erythromycin administration significantly improved gastric visualization while decreasing hospital stay, units of blood transfused, and need for a second endoscopy [9]. In 2013, another RCT was published with similar results to studies in the past [18]. In 2015, for the first time, the European Society of Gastrointestinal Endoscopy strongly recommended erythromycin administration prior to endoscopy in patients with severe or ongoing UGIB based on high quality evidence [21]. Despite this recommendation, practice outside of Europe may not have evolved.

In 2016, this updated meta-analysis adds to the overall evidence that erythromycin before endoscopy in UGIB patients by including all RCTs to-date. This meta-analysis demonstrated increased odds of gastric visualization while decreasing the odds of second-look endoscopy and length of hospital stay. In this meta-analysis, the mean units of blood transfusions did not differ as it has in past analyses. The likely reason is the significant heterogeneity that was apparent when the most recent study [18] was included. If this study was eliminated, the result would be significant without heterogeneity, suggesting that the mean units of blood transfused would likely be decreased with the use of pre-procedure erythromycin. This updated meta-analysis may influence parties outside of Europe to alter guidelines and practice.

However, despite including all the high quality RCTs published on the subject, this study has a few limitations. First, the doses of erythromycin varied among the studies, ranging from $125 \mathrm{mg}$ to $250 \mathrm{mg}$. However, this effect on overall outcomes was likely insignificant given that erythromycin in low doses $(70 \mathrm{mg}$ ) has been shown to accelerate gastric emptying [22]. Second, two of the four outcomes (gastric visualization and units of blood transfused) demonstrated significant heterogeneity. Compensation for this effect was performed by using a random effects model and sensitivity analysis. On sensitivity analysis, gastric visualization demonstrated similar results; however, units of blood transfused did not, as mentioned earlier, which may have impacted this result. Third, three studies utilized nasogastric lavage in both arms $[11,15,18]$. Given both arms was subjected to the same treatment with and without erythromycin, impact on overall results should be minimal. Fourth, gastric visualization was determined adequate or inadequate based on the authors' discretion for each study. Therefore, on pooling data for gastric visualization, only adequate versus inadequate was utilized and degrees of visualization beyond that was not assessed. Lastly, mortality was not assessed in the studies. This outcome would be particularly interesting but given the low mortality rate in UGIB, the studies did not have enough power to adequately assess this outcome.

In conclusion, erythromycin before endoscopy in patients with acute UGIB significantly improves gastric mucosa visualization while reducing hospital stay and the need for a second-look endoscopy. Based on the evidence, pre-endoscopic 


\section{Summary Box}

\section{What is already known:}

- Erythromycin has been shown to improve gastric motility

- Erythromycin administration prior to endoscopy in patients with upper gastrointestinal bleeding (UGIB) has been shown to be beneficial in improving visualization

- Guidelines are slow to adopt the use of erythromycin administration prior to endoscopy

\section{What the new findings are:}

- Erythromycin administration prior to endoscopy improved gastric visualization while reduced the need for second-look endoscopy and hospital stay

- Erythromycin administration should be highly considered in patients presenting with significant UGIB

- Guidelines should be updated to include this new evidence

administration of intravenous erythromycin in UGIB patients should be strongly considered with more guidelines being altered in the future to reflect this strong evidence.

\section{References}

1. Barkun AN, Bardou M, Kuipers EJ, et al. International consensus recommendations on the management of patients with nonvariceal upper gastrointestinal bleeding. Ann Intern Med 2010;152:101-113.

2. Gralnek IM, Jensen DM, Kovacs TO, et al. An economic analysis of patients with active arterial peptic ulcer hemorrhage treated with endoscopic heater probe, injection sclerosis, or surgery in a prospective, randomized trial. Gastrointest Endosc 1997;46:105112.

3. Laine L, Jensen DM. Management of patients with ulcer bleeding. Am J Gastroenterol 2012;107:345-360.

4. Lee SD, Kearney DJ. A randomized controlled trial of gastric lavage prior to endoscopy for acute upper gastrointestinal bleeding. J Clin Gastroenterol 2004;38:861-865.

5. Urbain JL, Vantrappen G, Janssens J, Van Cutsem E, Peeters T, De Roo M. Intravenous erythromycin dramatically accelerates gastric emptying in gastroparesis diabeticorum and normals and abolishes the emptying discrimination between solids and liquids. J Nucl Med 1990;31:1490-1493.
6. Barkun AN, Bardou M, Martel M, Gralnek IM, Sung JJ. Prokinetics in acute upper GI bleeding: A meta-analysis. Gastrointest Endosc 2010;72:1138-1145.

7. Bai Y, Guo JF, Li ZS. Meta-analysis: Erythromycin before endoscopy for acute upper gastrointestinal bleeding. Aliment Pharmacol Ther 2011;34:166-171.

8. Szary NM, Gupta R, Choudhary A, et al. Erythromycin prior to endoscopy in acute upper gastrointestinal bleeding: A metaanalysis. Scand J Gastroenterol 2011;46:920-924.

9. Theivanayagam S, Lim RG, Cobell WJ, et al. Administration of erythromycin before endoscopy in upper gastrointestinal bleeding: A meta-analysis of randomized controlled trials. Saudi J Gastroenterol 2013;19:205-210.

10. Higgins JPT, Green S. Cochrane handbook for systematic reviews of interventions. The Cochrane Collaboration 2011. http://handbook. cochrane.org/.

11. Carbonell N, Pauwels A, Serfaty L, Boelle PY, Becquemont L, Poupon R. Erythromycin infusion prior to endoscopy for acute upper gastrointestinal bleeding: a randomized, controlled, doubleblind trial. Am J Gastroenterol 2006;101:1211-1215.

12. Coffin B, Pocard M, Panis Y, et al. Erythromycin improves the quality of EGD in patients with acute upper GI bleeding: a randomized controlled study. Gastrointest Endosc 2002;56:174-179.

13. Frossard JL, Spahr L, Queneau PE, et al. Erythromycin intravenous bolus infusion in acute upper gastrointestinal bleeding: a randomized, controlled, double-blind trial. Gastroenterology 2002; 123:17-23.

14. Altraif I, Handoo FA, Aljumah A, et al. Effect of erythromycin before endoscopy in patients presenting with variceal bleeding: a prospective, randomized, double-blind, placebo-controlled trial. Gastrointest Endosc 2011;73:245-250.

15. Pateron D, Vicaut E, Debuc E, et al. Erythromycin infusion or gastric lavage for upper gastrointestinal bleeding: a multicenter randomized controlled trial. Ann Emerg Med 2011;57:582-589.

16. Rudzki S, Czekalowski S, Michalak K, Kusz W, Fularz A. Erythromycin improves quality of endoscopy for acute upper gastrointestinal bleeding. Wiad Lek 2006;59:490-491.

17. Habashi SL, Lambiase LR, Kottoor R. Prokinetics infusion prior to endoscopy for acute upper gastrointestinal bleeding: A randomized, controlled, double-blind \& placebo-controlled trial. Am J Gastroenterol 2007;102(S2):S526.

18. Javad Ehsani Ardakani M, Zare E, Basiri M, Mohaghegh Shalmani H. Erythromycin decreases the time and improves the quality of EGD in patients with acute upper GI bleeding. Gastroenterol Hepatol Bed Bench 2013;6:195-201.

19. Daram SR, Garretson R. Erythromycin is preferable to metoclopramide as a prokinetic in acute upper GI bleeding. Gastrointest Endosc 2011;74:234.

20. Standards of Practice Committee of the American Society for Gastrointestinal Endoscopy (ASGE). The role of endoscopy in the management of acute non-variceal upper GI bleeding. Gastrointest Endosc 2012:75:1132-1138.

21. Gralnek IM, Dumonceau JM, Kuipers EJ, et al. Diagnosis and management of nonvariceal upper gastrointestinal hemorrhage: European Society of Gastrointestinal Endoscopy (ESGE) Guideline. Endoscopy 2015;47:a1-46.

22. Ritz MA, Chapman MJ, Fraser RJ, et al. Erythromycin dose of $70 \mathrm{mg}$ accelerates gastric emptying as effectively as $200 \mathrm{mg}$ in the critically ill. Intensive Care Med 2005;31:949-954. 